\title{
A randomised controlled trial of the effectiveness of a breastfeeding training DVD on improving breastfeeding knowledge and confidence among healthcare professionals in China
}

\author{
Yuan Ying Ma ${ }^{* *}$, Louise L. Wallace ${ }^{2}$, Li Qian Qiu', Joanna Kosmala-Anderson ${ }^{3}$ and Naomi Bartle ${ }^{4}$
}

\begin{abstract}
Background: Despite almost all babies being breastfed initially, the exclusive breastfeeding rate at six months is less than 30\% in China. Improving professionals' knowledge and practical skill is a key government strategy to increase breastfeeding rates. This study aimed to test the effectiveness of a breastfeeding DVD training method for clinicians on improving their knowledge and confidence in the breastfeeding support skills of teaching mothers Positioning and Attachment ( $\mathrm{P} \& \mathrm{~A}$ ) and Hand Expression (HE).

Methods: A randomised controlled trial was conducted in three hospitals in Zhejiang province, China in 2014. Participants were recruited before their routine breastfeeding training course and randomly allocated to intervention group (IG) and control group (CG). The 15 min "Breastfeeding: Essential Support Skills DVD" was the intervention for IG and a vaginal delivery DVD was used for CG. All participants completed questionnaires of job information, knowledge and confidence in the two skills before (baseline) and immediately after viewing the DVD (post DVD).

Results: Out of 210 participants, 191 completed knowledge assessments before and after watching the DVD (IG $n=96$, CG $n=95$ ), with the response rate of $91.0 \%$. At baseline, there are no significant differences in job variables, total knowledge scores and confident scores. The total knowledge score significantly increased post-DVD for IG (pre-DVD: $M=5.39, S D=2.03$; post-DVD: $M=7.74, S D=1.71 ; t(95)=-10.95, p<0.01)$, but no significant change in total knowledge score for CG between pre- and post-DVD (pre-DVD: $M=5.67, S D=1.70$; post-DVD: $M=5.56, S D=1.63$; $t$ $(94)=0.85$ ). The total confidence scores were significantly higher post-DVD than pre-DVD in IG (pre-DVD: $M=66.49$, $S D=11.27$; post- DVD: $M=71.81, S D=9.33$; $\mathrm{t}(68)=-4.92, p<0.01)$, but no significant difference was seen in CG between pre- and post-DVD total confidence scores (pre-DVD: $M=68.33, S D=11.08$; post-DVD: $M=68.35, S D=11.40 ; t$ $(65)=-0.25)$. Personal and job variables did not mediate these effects.

Conclusions: The breastfeeding training DVD improved professionals' knowledge and confidence of the two breastfeeding support skills. However, the effect on professionals' practice and on breastfeeding outcomes needs to be examined in the future.
\end{abstract}

Keywords: Breastfeeding, DVD, Positioning, Attachment, Hand expression, Training, Midwives, Nurses, Maternity services

\footnotetext{
* Correspondence: mayuanying88@zju.edu.cn

'Women's hospital, School of Medicine, Zhejiang University, Xueshi Road 1\#,

Shangchen District, Hangzhou, Zhejiang Province, China

Full list of author information is available at the end of the article
} 


\section{Background}

There is strong global evidence for the short and long term health benefits of breastfeeding for infants and mothers [1-7]. Breastfeeding is recommended as the healthiest way to feed an infant by the World Health Organization (WHO) and UNICEF [8]. It is estimated that globally approximately 800,000 child lives would be saved each year if all children were fed according to the recommendations of the WHO and UNICEF [http://www.who. int/features/factfiles/breastfeeding/en/]. Therefore, promoting breastfeeding and increasing breastfeeding rates has become a global strategy to improve children's health. Many governments are implementing various interventions to achieve national breastfeeding goals. In China, the National Programme of Action for Children's Development (NPA) has set national targets for exclusive breastfeeding rates at six months to improve children's health and development every ten years since 1990. The new target set by NPA for 2011-2020 is to increase the exclusive breastfeeding rate for infants aged 0-6 months to over 50\% [http:/www.gov.cn/gongbao/content/2011/content_ 1927200.htm]. However, the National Health and Family Planning Commission (NHFPC) reported the latest rate of exclusive breastfeeding at six months to be $30 \%$ in rural areas and 16\% in urban areas in 2014 [http://www.women ofchina.cn/womenofchina/html1/17/3045-1.htm].

Returning to work and insufficient breast milk are reported by mothers to be the main reasons for ceasing breastfeeding early according according to $\mathrm{Xu}$ and colleagues who reviewed breastfeeding rates and practices in China in 41 cohort and cross sectional studies published between 1990 and 2009, and included large sample sizes [9].

The cross-sectional study by Cannon indicated that the importance of intra-oral vacuum in effective and efficient milk removal during breastfeeding. Incorrect attachment affect the removal of milk due to low vacuum [10].Ineffective removal of breast milk with incorrect positioning and attachment ( $\mathrm{P} \& \mathrm{~A}$ ) wi leads to an increase in the feedback inhibitor of lactation (FIL), which is produced by the lactocytes and regulates the production of breast milk. As FIL increases, breast milk production will decrease $[11,12]$. In addition, poor attachment leads to sore nipples, engorgement, mastitis and poor weight gain as the tongue is not placed over the lower gum and the gums placed over the lactiferous sinuses [13, 14], which inhibits effective milk removal from the breast. Hand Expression (HE) is an essential skill for mothers who cannot breastfeed their infants directly due to their own or their baby's illness, infants' separation from mothers or preterm birth [15-17]. HE is also used to stimulate breast milk production when the amount of breast milk seems to be insufficient [18]. Enhancing professionals' skills in $\mathrm{P} \& \mathrm{~A}$ and $\mathrm{HE}$ are essential for supporting breastfeeding mothers, but the challenge of training many thousands of maternity clinicians across China will require new approaches to training.

$\mathrm{P} \& \mathrm{~A}$ and $\mathrm{HE}$ are two essential skills to ensure mothers breastfeed successfully, and such that they are a required part of the curriculum for training all maternity staff to enable all mothers to use these skills, which forms part of the "Ten Steps" of the UNICEF Baby Friendly Hospital Initiative (BFHI) accreditation [19], [http://www.unicef.org/nutrition/index_24806.html]. The key technique of P \& A when it was taught by skilled professionals antenatally was associated with increased breastfeeding rates for as long as six months after birth among 70 mothers in a small pilot study in Western Australia [20, 21]. However, two national surveys in the UK indicated that family doctors, paediatric clinicians and nursing and midwifery clinicians often believe they have inadequate knowledge and insufficient training in breastfeeding support including teaching P \& A [22, 23].

In China, there have been no studies outside of our research specifically assessing clinicians' knowledge and skill in teaching mothers $\mathrm{P} \& \mathrm{~A}$ and HE. However, Ouyang undertook a survey to investigate the knowledge of a range of breastfeeding topics among 600 Chinese female physicians and nurses from 10 randomly selected BFHI hospitals in Hubei province in 2009 [24]. The knowledge assessment used statements which were scored true or false, and covered the benefits of breastfeeding, reliable signs of adequate breast milk, demand feeding and recommended duration of breastfeeding. The results showed most clinicians had surprisingly poor knowledge of breastfeeding, and $79.3 \%$ of clinicians had received no breastfeeding training since they began working in maternity hospitals. In 2014, a spokesman from UNICEF China said that there are a lack of skilled professionals in hospital and community servces to satisfy an emerging group of women in China who are eager to breastfeed [http://www.womenofchina.cn/ womenofchina/html1/17/3045-1.htm]. Watkins and Dodgson suggested that one of the most efficient strategies for increasing breastfeeding duration and exclusive breastfeeding according to previous systematic reports was effective breastfeeding training for professionals [25]. A recent review of 1192 studies aimed to identify whether education and training programs for healthcare staff have an effect on their knowledge and attitudes about supporting breastfeeding women. However, the review was inconclusive due to low study quality. Therefore, robust research design is necessary in future research [26].

The current study was designed to assess the specific knowledge and confidence to practise the skills of P \& A and HE. It also tested whether training clinicians with a short breastfeeding DVD can improve their knowledge 
and confidence in their practice. Researchers in the UK developed an evidence-based training programme consisting of a 10-12 h self-study breastfeeding workbook, a DVD teaching the two essential breastfeeding support skills of P \& A and HE and used the Coventry University Breastfeeding Assessment tool (CUBA) to meet the requirements of UK UNICEF BFI accreditation standards in England [27-30]. Both have been tested with 322 midwifery and nursing clinicians in two maternity and community services in the West Midlands of England [30].The current research study is unique in China, using an objective method of assessment and a training DVD that has already been found to be effective the UK.

The current study aimed to test if the short DVD training programme is effective in improving Chinese clinicians' knowledge and confidence in the specific skills of P \& A and HE skills compared to controls not given the training but conducting the same repeated assessments of knowledge and confidence.

\section{Methods}

\section{Intervention}

The breastfeeding training DVD developed by the researchers in England was the training intervention for healthcare professionals in the study. It covers four educational sessions, including optimal P \& A, the process of a satisfying feed shown by a baby of three months, hand expression demonstrated by a mother, and babyled feeding demonstrated by an experienced baby of ten months. The total length of the DVD is $14 \mathrm{~min} 32 \mathrm{~s}$ [29]. The Mandarin script of the breastfeeding trainers' voice-over explaining the learning points of the DVD was developed by the lead author based on the English script version, and agreed with two breastfeeding experts and one professional translator. Two staff in Zhejiang University of Media and Communications recorded and produced the Mandarin version of the breastfeeding training DVD according to the Mandarin script.

\section{Design}

The study tests the effect of the Intervention Group (IG) watching the Breastfeeding DVD designed to educate clinicians to facilitate the development of knowledge and confidence in the skills of supporting mothers in P \& A and HE compared to a Control Group (CG) of clinicians who watch a DVD about vaginal birth of similar duration on clinicians' total knowledge of PA and HE (primary outcome) and confidence in $\mathrm{P} \& \mathrm{~A}$ and $\mathrm{HE}$ (secondary outcomes) in a randomised controlled trial. The baseline measures were administered immediately before watching the DVD, and post intervention measures were taken immediately after watching the DVD. A power analysis was carried out to determine the required sample size in the study based on the a result of a pilot study among Chinese professionals conducted by the lead author [31]. The observed effect size was large $(\mathrm{d}=1.05)$ for the $\mathrm{t}$-test on change in total knowledge scores (primary outcome) between pre- and post-DVD. $G^{*}$ Power was used to calculate the required sample size to detect a condition by time interaction in ANOVA with a medium-to-large effect size $(F=0.30)$ [32]. In order to achieve $90 \%$ power, with significance level set at 5\%, a total of 119 participants were required. We sought to invite approximately 200 participants to allow for $40 \%$ attrition.

\section{Setting}

The study was conducted in Zhejiang Province, China. Participants were recruited from those clinicians about to attend a breastfeeding training course. They are all from three hospitals, including Women's Hospital, School of Medicine, Zhejiang University, Kaihua county maternal and child health care hospital, and Kaihua county general hospital. The Women's Hospital, School of Medicine, Zhejiang University is the largest and highest level teaching tertiary hospital for maternal health care in Zhejiang Province. The other two hospitals are secondary county hospitals in Kaihua county. All three hospitals are accredited as BFHI hospitals.

\section{Sample}

Qualified health professionals (doctors, nurses and midwives) in Zhejiang Province who work with breastfeeding women were included. Staff who were not directly caring for breastfeeding mothers or volunteer for supporting breastfeeding mothers were excluded.

\section{Procedure}

The study was conducted before two breastfeeding training courses during March and June 2014. The researcher obtained the lists of names of all the participants who would take part in the provincial and county breastfeeding training courses. There was a staff member in each hospital who co-ordinated the study and emailed potential participants with an invitation to take part in the study. Those professionals who had no email address or did not reply to the invitation email were invited by telephone. The reasons for declining the invitation were recorded by the staff member. Participants who met the eligibility criteria and agreed to participate in each hospital were randomly allocated by a researcher blind to the two conditions to an intervention group (IG) and a control group (CG) using SPSS software by a computer professional in Zhejiang University. Randomisation was for the whole sample not by site. See Fig. 1 .

All the participants received a sealed envelope marked Group 1 (IG) or Group 2 (CG), in which there was information for participants about the study, consent form, 


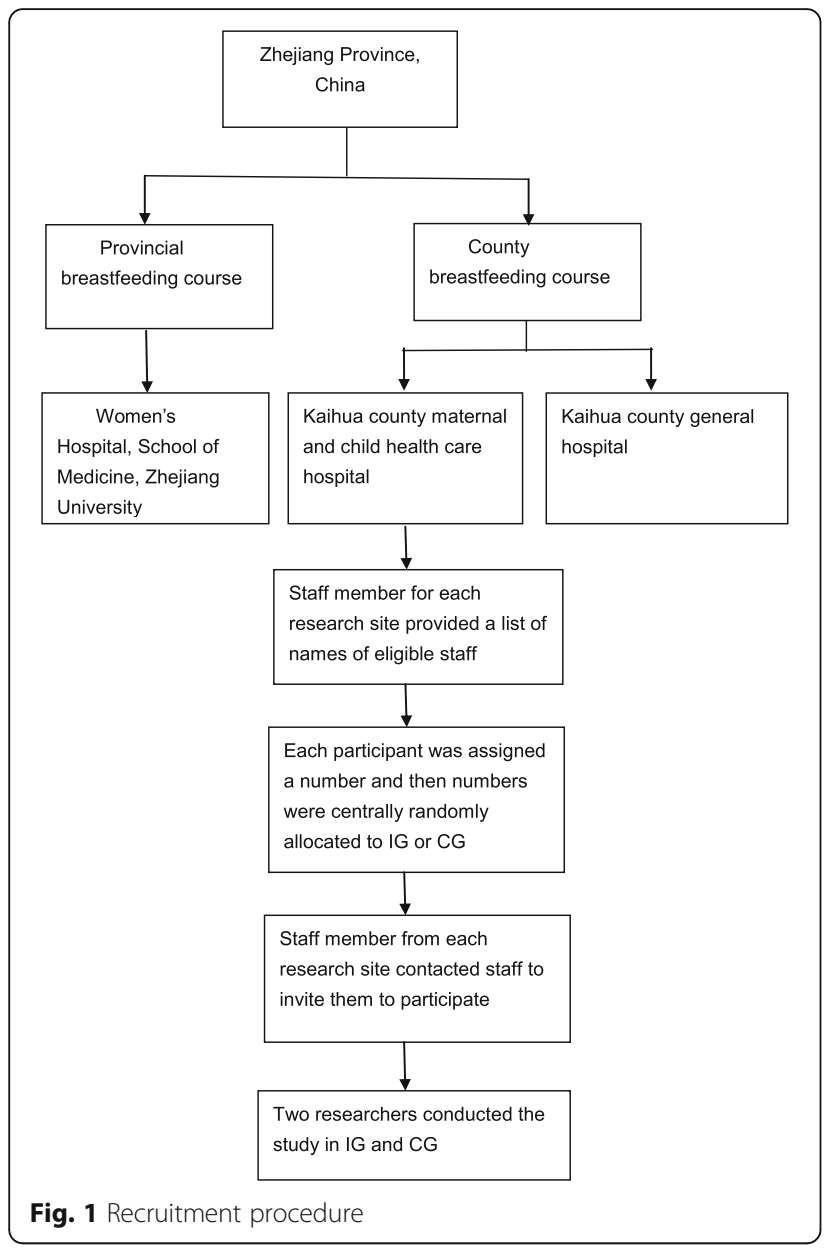

pre-DVD training questionnaire and post-DVD training questionnaire, both with a coded number sequence. Participants were not aware until they saw the DVD which group they were randomly allocated to in order to minimize disruption to the training courses, and they were informed they could withdraw consent at any time. The two groups were allocated to different rooms at the same time point and separate researchers explained the aims, methods and use of their data in line with the written information provided, and supervised the signing of consent forms. Pre-DVD training assessments (baseline questionnaire) were carried out for all participants before they watched the DVD. The baseline questionnaires were collected by the researchers immediately after being completed. Any one who withdrew consent to participate was asked to leave the room and wait for the training course. Next, the participants in the intervention group watched the Mandarin version of the breastfeeding training DVD. The control group watched a DVD in Mandarin unrelated to breasteeding about vaginal delivery. Both DVDs are of about $15 \mathrm{~min}$. After watching their respective DVDs, participants in both intervention and control groups completed the post DVD training assessments.

\section{Measures \\ Knowledge}

The level of knowledge of breastfeeding in P \& Aand HE was assessed using a Mandarin version of mini-CUBA based on the Coventry University Breastfeeding Assessment (CUBA) used in a previously published study [29]. The items of mini-CUBA were multiple-choice questions with only one answer correct of four options, which had been agreed by a panel of three breastfeeding experts. There were six items where a correct answer is scored as 1 of $\mathrm{P} \& \mathrm{~A}$ knowledge (range 0-6) and six items of HE knowledge (range 0-6). A higher score indicated a higher knowledge level.

\section{Confidence}

The confidence of healthcare professionals in skills for supporting breastfeeding mothers was measured using the Mandarin version of Coventry University Breastfeeding Support Self-Efficacy Scale (CU-BSSES) [29]. It measures six items of self-efficacy in supporting $\mathrm{P} \& \mathrm{~A}$ and two items on teaching $\mathrm{HE}$, using a 10 -point Likert scale $(1=$ not at all confident; $10=$ completely confident). CU-BSSES was used to assess the breastfeeding confidence among healthcare professionals in supporting the two skills of P \& A and HE. Cronbach alpha coefficient value of 0.95 in this sample suggests a good internal reliability of CU-BSSES for the sub scale and total scale scores.

\section{Job specific survey items}

There were two personal and six job specific items: gender, age, work setting, job type, job title, years of qualification, working length with breastfeeding mothers, previous breastfeeding training. This was administered only at the baseline, along with knowledge and confidence measures. The post-training questionnaire comprised only the knowledge and confidence measures. The knowledge assessments of $\mathrm{P} \& \mathrm{~A}$ and $\mathrm{HE}$ in the pre- and post-training questionnaires were the same. The change in scores of knowledge regarding the two skills of $\mathrm{P} \& \mathrm{~A}$ and $\mathrm{HE}$ in pre- and post-training questionnaires were the primary outcome to assess the effectiveness of the breastfeeding training DVD.

\section{Analysis}

Epidata (3.1) was used for double entry of data and the accuracy of entries was checked. Statistical Package for Social Science (SPSS version 22. 0) was used to analyse the data and the level of statistical significance was set at $p<0.05$. Cases were excluded if they were missing data on any variable included in the specific analysis. 
For statistically significant groups, the strength of association was assessed by effect size to provide the magnitude of the differences between groups [33, 34]. Cronbach's alpha coefficient was examined and reported the internal consistency for the Breastfeeding Support Self-Efficacy Scale. Chi-square tests compared the differences of each personal and job variable between the intervention and control groups. Mixed 2way analysis of variance (ANOVA) were conducted to explore the interaction between group and time (prepost DVD) for each dependent variable (PA knowledge, PA confidence, HE knowledge and $\mathrm{HE}$ confidence). Independent-Samples $\mathrm{T}$ Test was used to examine the differences in the mean score of knowledge and confidence between the two groups, and before and after viewing the DVD. The changes in total score of knowledge and confidence in the two skills in the intervention group by personal and job type variables was analysed by mixed ANOVA.

\section{Results}

\section{Characteristics of participants}

Between March and June 2014, a total of 216 names were provided by the staff members at the research sites, including118 professionals participating provincial breastfeeding training course and 98 professionals in county training course. Six professionals were not eligible and were excluded as they worked in an administrative department. Nine staff declined to participate before the study with two staff stating they were not interested, and seven staff said they did not have time to participate in the study. The remaining 201 eligible staff were invited to take part in the study. Five professionals who were late for the breastfeeding training course did not participate in the study with 2 staff of IG and 3 staff of CG. Two clinicians did not complete the post-training questionnaires as they left early. Three post-training questionnaires were excluded during analysis due to half or more uncompleted items. The final sample included

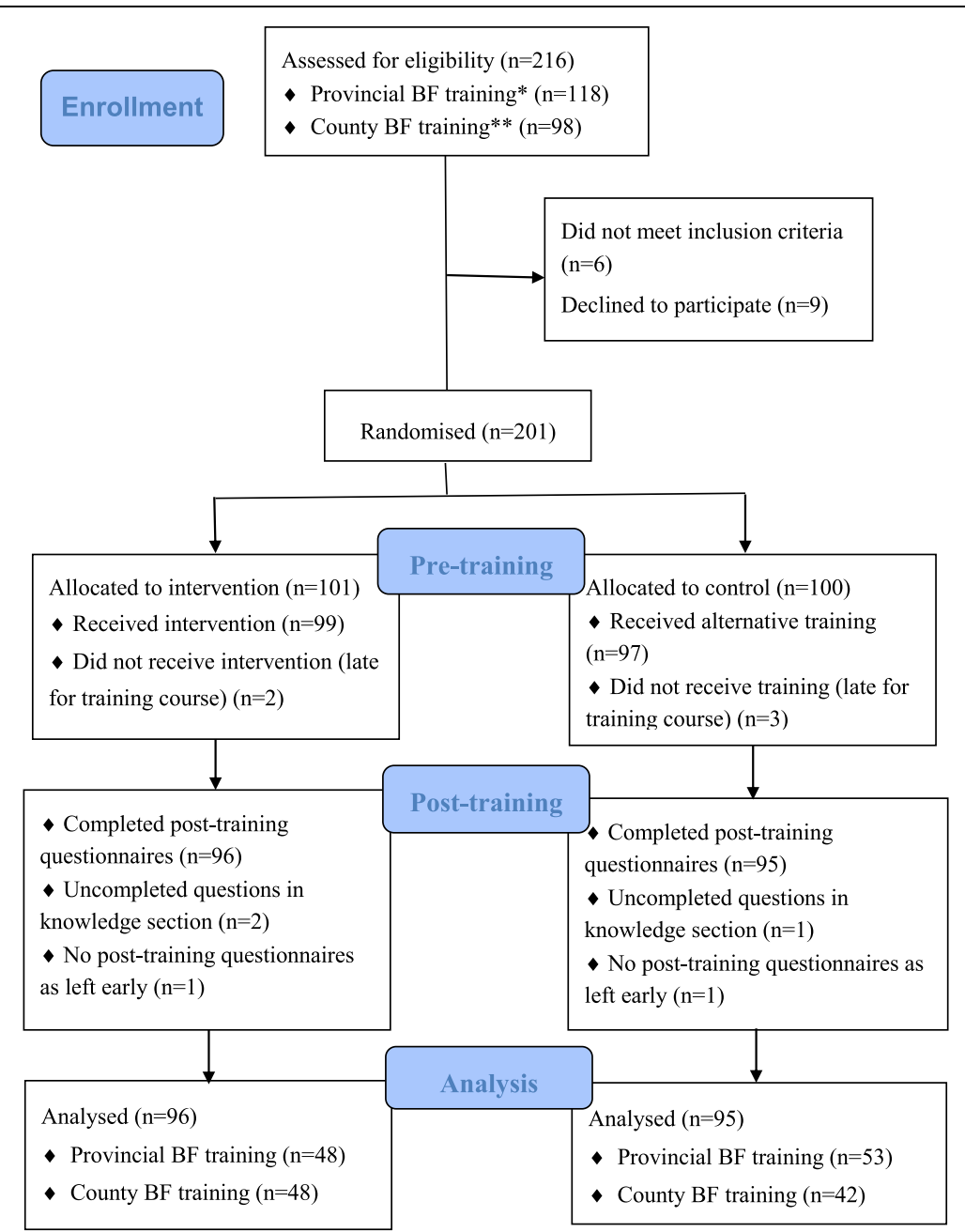

Fig. 2 RCT Flow Diagram. *Participants in Provincial BF training were from Women's Hospital, School of Medicine, Zhejiang University. ** Participants in County BF training were from Kaihua county maternal and child health care hospital and Kaihua county general hospital 
191 healthcare professionals who watched the allocated DVD and completed the pre- and post-DVD training questionnaires: 96 in the IG and 95 in CG. The response rate was $91 \%$ (See Fig. 2).

The 191 participants covered a spread of professions, including 91 (47.6\%) nurses, 39 (20.4\%) midwives, 61 (32.0\%) doctors. Most participants were female except five male doctors, as almost all professionals who work with breastfeeding mothers in China are female. These participants were diverse in age, work setting, job title, job type, length of time working with breastfeeding mothers, years since obtaining their professional qualification and previous breastfeeding training. The mean age of the participants was 33.51 years $(\mathrm{SD}=8.17)$, however there was missing data for 51 cases for age. There were 101 (52.9\%) working in provincial hospitals and 90 (47.1\%) worked in county hospitals. There were 94 (49. 2\%) participants that had achieved mid-grade or higher titles and 97 (50.8\%) participants had primary junior titles, i.e. those who were in their first post qualification job role). Furthermore, 90 (47.1\%) participants had received their qualifications more than 5 years ago, and 101 (52.9\%) participants less than 5 years. Some 132 (69. $1 \%)$ participants had worked with breastfeeding mothers for more than two years, and 75 (39.3\%) participants had worked for more than ten years. Of the study sample, 132 (69.5\%) participants had had previous breastfeeding training and 58 (30.5\%) participants had had no breastfeeding training prior to the training course. There were no significant differences on any of these variables between the two groups. (See Table 1).

\section{Pre DVD knowledge and confidence scores in IG and CG} At pre DVD baseline, there was no statistical difference in $\mathrm{P} \& \mathrm{~A}, \mathrm{HE}$ and total knowledge score between IG and CG. There was missing data from 48 participants on the confidence measure at either pre or post -test, so confidence analyses were restricted to 143 cases. At pre-test there was missing data for 25/96 participants in the IG, and 19/95 in the CG, in the post-test there was missing data for 4/96 in the IG and 14/95 in the CG. The total confidence score and $\mathrm{P} \& \mathrm{~A}$ confidence score at baseline showed no significant difference between IG and CG. However, the HE confidence score at baseline was significantly higher in the CG compared with IG. This data is available from the authors.Therefore change scores on knowledge and confidence are used in further analyses.

Table 1 Characteristics of the professionals participating in the evaluation of the breastfeeding training DVD

\begin{tabular}{|c|c|c|c|c|}
\hline Characteristics & & $\begin{array}{l}\text { IG } \\
n=96(\%)\end{array}$ & $\begin{array}{l}\text { CG } \\
n=95(\%)\end{array}$ & $\begin{array}{l}X^{2} \text { and } \\
p \text {-value }\end{array}$ \\
\hline \multirow[t]{3}{*}{ Age } & $<30$ years & $22(22.9)$ & $24(25.3)$ & \multirow{3}{*}{$\begin{array}{l}3.84 \\
p=0.15\end{array}$} \\
\hline & 30-39 years & $35(36.5)$ & $26(27.4)$ & \\
\hline & $\begin{array}{l}>39 \text { years } \\
\text { Missing }\end{array}$ & $\begin{array}{l}12(12.5) \\
27(28.1)\end{array}$ & $\begin{array}{l}21(22.1) \\
24(25.3)\end{array}$ & \\
\hline \multirow[t]{2}{*}{ Working hospital } & Provincial hospital & $48(50)$ & $53(55.8)$ & \multirow{2}{*}{$\begin{array}{l}0.01 \\
p=0.92\end{array}$} \\
\hline & County hospital & $48(50)$ & $42(44.2)$ & \\
\hline \multirow[t]{3}{*}{ Job type } & Nurse & $46(47.9)$ & $45(47.4)$ & \multirow{3}{*}{$\begin{array}{l}0.38 \\
p=0.83\end{array}$} \\
\hline & Midwife & $32(33.3)$ & $29(30.5)$ & \\
\hline & Doctor & $18(18.8)$ & $21(22.1)$ & \\
\hline \multirow[t]{2}{*}{ Job title } & Senior or mid-grade & $48(50.0)$ & $46(48.5)$ & \multirow{2}{*}{$\begin{array}{l}0.05 \\
p=0.83\end{array}$} \\
\hline & Junior grade & $48(50.0)$ & $49(51.5)$ & \\
\hline \multirow[t]{2}{*}{ Years since qualification } & $\leq 5$ years & $43(44.8)$ & $47(49.5)$ & \multirow{2}{*}{$\begin{array}{l}0.53 \\
p=0.47\end{array}$} \\
\hline & $>5$ years & $53(55.2)$ & $48(50.5)$ & \\
\hline \multirow[t]{4}{*}{ Year of working with breastfeeding mothers } & $\leq 2$ years & $23(24.0)$ & $30(31.6)$ & \multirow{4}{*}{$\begin{array}{l}0.44 \\
p=0.80\end{array}$} \\
\hline & $3-10$ years & $33(34.4)$ & $24(25.3)$ & \\
\hline & $>10$ years & $36(37.5)$ & $39(41.1)$ & \\
\hline & Missing & $4(4.2)$ & $2(2.1)$ & \\
\hline \multirow[t]{3}{*}{ Previous training on breastfeeding } & Yes & $67(69.8)$ & $65(68.4)$ & \multirow{3}{*}{$\begin{array}{l}0.01 \\
p=0.92\end{array}$} \\
\hline & No & $29(30.2)$ & $29(30.5)$ & \\
\hline & Missing & $0(0.0)$ & $1(1.1)$ & \\
\hline
\end{tabular}


Knowledge scores changes between pre- and post-DVD in IG and CG

Using ANOVA (Group $\mathrm{x}$ Time) there was significant interaction between group and time in total knowledge score $\left[\mathrm{F}(1,188)=92.11, \quad p<0.001, \quad \eta^{2}=.33.\right], \quad \mathrm{P} \& \mathrm{~A}$ knowledge score $\left[\mathrm{F}(1,189)=48.02, p<0.001, \eta^{2}=.20\right]$ and HE knowledge score $\left[\mathrm{F}(1,189)=48.65, p<0.001, \eta^{2}=.21\right]$. T-tests showed that in the IG there was a significant increase in total knowledge, P \& A knowledge and HE knowledge after completing the DVD training, with large effect sizes (see Table 2). However, there was no significant change in total knowledge PA knowledge or HE knowledge control group (Table 2).The $\eta^{2}$ values $(>0.4)$ indicate large increases in knowledge in the IG group.

\section{Confidence scores changes between pre- and post-DVD in IG and CG}

There were 135 participant completed the pre-post confidence assessment. The participants' characteristics of those with complete data were compared with those with missing data and no difference observed. There was a significant interaction between group and time (prepost DVD) in total confidence score $[\mathrm{F}(1,133)=17.92, p$ $\left.<0.001, \eta^{2}=0.26\right], P \&$ A confidence score $\mathrm{F}(1,133)=15$. 66, $\left.p<0.001, \quad \eta^{2}=0.26\right]$ and HE confidence score $\left[\mathrm{F}(1,135)=13.90, p<0.001, \eta^{2}=0.20\right]$. T-tests revealed a significant increase in the $\mathrm{P} \& \mathrm{~A}$ confidence scores was found post-DVD compared to pre-DVD in the IG, but not the CG (see Table 3$)$. The Eta squared value $(>0.2)$ indicate large increases in confidence in the IG group.

\section{Sub group analyses on change in knowledge scores of the intervention group}

Table 4 shows the change in total knowledge scores in the IG. All the sub-groups (within-subjects) achieved significantly increased total knowledge scores post-DVD compared to pre-DVD. A significantly higher increase in total knowledge score was seen among the participants working in county hospitals or less specialised (lower level) hospitals compared to participants in provincial or municipal hospitals. There was also a significant sub group effect (interaction) for job type. Inspecting the mean scores shows doctors achieved a greater increase in total knowledge score compared to midwives and nurses. However, the post hoc showed no significant differences in increased total knowledge scores between doctor and midwife, or doctor and nurse, or nurse and midwife. There were no significant differences in the change in knowledge scores for other sub-group variables, including age, seniority of job (job title), length of time working with breastfeeding mothers, years since obtaining professional qualification and previous breastfeeding training.

Table 5 shows the impact of the breastfeeding training DVD on the change of mean confidence scores in the sub-groups of the intervention group from pre-training to post-training. Cases were deleted where data was missing on one or more variable. All the sub-groups in the IG obtained significantly increased total confidence scores post-DVD compared to pre-DVD. No significant differences in mean confidence scores were found for any sub-groups of personal and job-related variables. (See Table5).

\section{Discussion}

This is the first randomised controlled trial of the effectiveness of a DVD training programme on improving breastfeeding knowledge and confidence in practice of the two key skills of P \& A and HE among professionals in China. We were able to show that the effect is not simply attributable to practise on the knowledge assessment and confidence ratings, since there was no test and retest effect in the CG. Second, the increases were statistically significant in the IG. Further, the improvements were shown for all types of staff when analysed by personal and job variables.

In conducting the RCT, every effort was made to prevent known sources of bias. Randomisation was conducted independently of the researchers, trainers and participants. Allocation concealment was maintained so participants were blind to allocation until after the baseline data was collected. Analyses showed that groups were balanced for personal and job

Table 2 Comparison of the differences in knowledge scores between pre- and post-DVD in intervention group and control group

\begin{tabular}{|c|c|c|c|c|c|c|}
\hline \multirow[t]{2}{*}{ Items } & \multicolumn{3}{|l|}{ IG $(n=96)$} & \multicolumn{3}{|l|}{$C G(n=95)$} \\
\hline & $\begin{array}{l}\text { Pre- } \\
\text { DVD } \\
\text { mean (SD) }\end{array}$ & $\begin{array}{l}\text { Post- } \\
\text { DVD } \\
\text { mean (SD) }\end{array}$ & $t$ test & $\begin{array}{l}\text { Pre- } \\
\text { DVD } \\
\text { mean (SD) }\end{array}$ & $\begin{array}{l}\text { Post- } \\
\text { DVD } \\
\text { mean (SD) }\end{array}$ & $t$ test \\
\hline $\begin{array}{l}P \& A \\
\text { (range 0-6) }\end{array}$ & $2.73(1.41)$ & $\begin{array}{l}4.04 \\
(1.16)\end{array}$ & $\begin{array}{l}\mathrm{t}(95)=-8.29 \\
p<0.01\end{array}$ & $\begin{array}{l}2.86 \\
(1.37)\end{array}$ & $\begin{array}{l}2.83 \\
(1.19)\end{array}$ & $\begin{array}{l}\mathrm{t}(94)=0.28 \\
p=0.78\end{array}$ \\
\hline $\begin{array}{l}\text { HE } \\
\text { (range 0-6) }\end{array}$ & $2.66(1.09)$ & $3.70(1.00)$ & $\begin{array}{l}\mathrm{t}(95)=-8.13 \\
p<0.01\end{array}$ & $\begin{array}{l}2.81 \\
(1.13)\end{array}$ & $\begin{array}{l}2.73 \\
(1.19)\end{array}$ & $\begin{array}{l}\mathrm{t}(94)=0.86 \\
p=0.39\end{array}$ \\
\hline $\begin{array}{l}\text { Total } \\
\text { (range 0-12) }\end{array}$ & $\begin{array}{l}5.39 \\
(2.03)\end{array}$ & 7.74 (1.71) & $\begin{array}{l}\mathrm{t}(95)=-10.95 \\
p<0.01\end{array}$ & $\begin{array}{l}5.67 \\
(1.70)\end{array}$ & $\begin{array}{l}5.56 \\
(1.62)\end{array}$ & $\begin{array}{l}\mathrm{t}(94)=0.85 \\
p=0.40\end{array}$ \\
\hline
\end{tabular}


Table 3 Comparison of differences in confidence scores between pre- and post-DVD in intervention group and control group

\begin{tabular}{|c|c|c|c|c|c|c|}
\hline \multirow[t]{2}{*}{ Items } & \multicolumn{3}{|l|}{ IG $(n=69)$} & \multicolumn{3}{|l|}{ CG $(n=66)$} \\
\hline & $\begin{array}{l}\text { Pre- } \\
\text { DVD } \\
\text { mean (SD) }\end{array}$ & $\begin{array}{l}\text { Post- } \\
\text { DVD } \\
\text { mean (SD) }\end{array}$ & $p$-value & $\begin{array}{l}\text { Pre- } \\
\text { DVD } \\
\text { mean (SD) }\end{array}$ & $\begin{array}{l}\text { Post- } \\
\text { DVD } \\
\text { Mean (SD) }\end{array}$ & $p$-value \\
\hline $\begin{array}{l}P \& A \\
\text { (range 0-60) }\end{array}$ & $49.93(8.48)$ & $\begin{array}{l}53.90 \\
(6.93)\end{array}$ & $\begin{array}{l}\mathrm{t}(68)=-4.79 \\
p<0.01\end{array}$ & $\begin{array}{l}50.68 \\
(8.62)\end{array}$ & $\begin{array}{l}50.82 \\
(8.89)\end{array}$ & $\begin{array}{l}\mathrm{t}(65)=-0.36 \\
p=0.72\end{array}$ \\
\hline $\begin{array}{l}\mathrm{HE} \\
\text { (range 0-20) }\end{array}$ & $16.57(3.29)$ & $17.91(2.51)$ & $\begin{array}{l}\mathrm{t}(68)=-4.12 \\
p<0.01\end{array}$ & $17.59(2.85)$ & $17.49(2.77)$ & $\begin{array}{l}\mathrm{t}(67)=0.49 \\
p=0.62\end{array}$ \\
\hline $\begin{array}{l}\text { Total } \\
\text { (range 0-80) }\end{array}$ & 66.49 (11.27) & 71.81 (9.33) & $\begin{array}{l}\mathrm{t}(68)=-4.92 \\
p<0.01\end{array}$ & $68.33(11.08)$ & $\begin{array}{l}68.35 \\
(11.40)\end{array}$ & $\begin{array}{l}\mathrm{t}(65)=-0.25 \\
p=0.98\end{array}$ \\
\hline
\end{tabular}

Cases were deleted where there was missing data on the dependent variable

variables which might have affected baseline levels of knowledge. Missing data was evenly distributed between control and intervention groups. No significant differences in the mean score of knowledge and confidence were found between groups in two areas of $\mathrm{P}$ \& A, except that the control group had higher baseline confidence in HE than the IG group before they watched a DVD. Participants came from a range of maternity services in Zhejiang Province, and a range of clinical professions, with differing lengths of experience of working with breastfeeding mothers, time since gaining their qualifications and levels of prior breastfeeding training. Thus, the sample was broadly representative of the healthcare professionals supporting breastfeeding mothers in Zhejiang Province, and with a high response rate.

\section{Knowledge}

The study showed a large range of knowledge scores and poor knowledge level at baseline. The mean scores were less than half of the total possible correct scores at baseline among participants in total. Although clinical staff in BFHI accredited hospitals are expected to be trained in breastfeeding support as soon as they are employed in a clinical role with mothers, this study suggests many women will be exposed to clinical staff with insufficient knowledge of these essential skills. Such results are perhaps to be expected, given the acknowledged shortfalls in implememtaion of BFHI in China referred to above [24, 35].

The study indicates the new DVD training method is effective in improving professionals' knowledge in each area of P \& A, HE. Improvements in mean knowledge

Table 4 Change in the total knowledge scores in sub-group variables of intervention group between pre- and post-training

\begin{tabular}{|c|c|c|c|c|c|c|}
\hline Items & & Number & $\begin{array}{l}\text { Pre-DVD } \\
\text { mean (SD) } \\
\text { (range 0-12) }\end{array}$ & $\begin{array}{l}\text { Post-DVD } \\
\text { mean (SD) } \\
\text { (range 0-12) }\end{array}$ & $\begin{array}{l}\text { ANOVA } \\
\text { (interaction effect) }\end{array}$ & $\begin{array}{l}\text { ANOVA } \\
\text { (within-subject effect) }\end{array}$ \\
\hline \multirow[t]{3}{*}{ Age } & $<30$ years & 22 & $5.55(1.57)$ & $7.18(1.40)$ & \multirow{3}{*}{$\begin{array}{l}F(2,66)=0.80 \\
p=0.45\end{array}$} & \multirow{3}{*}{$\begin{array}{l}F(1,66)=64.33 \\
p<0.01\end{array}$} \\
\hline & $30-39$ years & 35 & $5.66(2.16)$ & $7.94(1.73)$ & & \\
\hline & $>39$ years & 12 & $5.25(2.53)$ & $7.33(1.88)$ & & \\
\hline \multirow[t]{2}{*}{ Working hospital } & Provincial or municipal hospital & 35 & $6.31(1.81)$ & $7.94(1.64)$ & \multirow{2}{*}{$\begin{array}{l}F(1,94)=6.94 \\
p=0.01\end{array}$} & \multirow{2}{*}{$\begin{array}{l}F(1,94)=102.95 \\
p<0.01\end{array}$} \\
\hline & County hospital or below & 61 & $4.85(1.97)$ & $7.62(1.74)$ & & \\
\hline \multirow[t]{3}{*}{ Job type } & Nurse & 46 & $5.57(1.97)$ & $7.67(1.52)$ & \multirow{3}{*}{$\begin{array}{l}F(2,93)=3.06 \\
p=0.05\end{array}$} & \multirow{3}{*}{$\begin{array}{l}F(1,93)=102.83 \\
p<0.01\end{array}$} \\
\hline & Midwife & 18 & $6.28(2.05)$ & $8.00(2.17)$ & & \\
\hline & Doctor & 32 & $4.63(1.90)$ & $7.69(1.71)$ & & \\
\hline \multirow[t]{2}{*}{ Job title } & Senior or mid-grade & 48 & $5.71(2.25)$ & $8.06(1.93)$ & \multirow{2}{*}{$\begin{array}{l}F(1,94)=0.00 \\
p=1.00\end{array}$} & \multirow{2}{*}{$\begin{array}{l}F(1,94)=118.52 \\
p<0.01\end{array}$} \\
\hline & Primary & 48 & $5.06(1.76)$ & $7.42(1.40)$ & & \\
\hline \multirow[t]{2}{*}{ Years since qualification } & $\leq 5$ years & 42 & $5.48(1.71)$ & $7.43(1.53)$ & \multirow{2}{*}{$\begin{array}{l}F(1,93)=2.67 \\
p=0.11\end{array}$} & \multirow{2}{*}{$\begin{array}{l}F(1,93)=113.15 \\
p<0.01\end{array}$} \\
\hline & $>5$ years & 53 & $5.30(2.28)$ & $7.96(1.82)$ & & \\
\hline \multirow[t]{3}{*}{ Years working with BF mothers } & $\leq 2$ years & 23 & $5.39(1.85)$ & $7.22(1.57)$ & \multirow{3}{*}{$\begin{array}{l}F(2,89)=0.93 \\
p=0.40\end{array}$} & \multirow{3}{*}{$\begin{array}{l}F(1,89)=100.48 \\
p<0.01\end{array}$} \\
\hline & $3-10$ years & 33 & $5.09(1.93)$ & $7.70(1.69)$ & & \\
\hline & $>10$ years & 36 & $5.81(2.27)$ & $8.14(1.81)$ & & \\
\hline \multirow[t]{2}{*}{ Previous training on breastfeeding } & Yes & 67 & $5.87(1.95)$ & $7.96(1.75)$ & \multirow{2}{*}{$\begin{array}{l}F(1,94)=3.59 \\
p=0.06\end{array}$} & \multirow{2}{*}{$\begin{array}{l}F(1,94)=119.62 \\
p<0.01\end{array}$} \\
\hline & No & 29 & $4.28(1.81)$ & $7.24(1.53)$ & & \\
\hline
\end{tabular}


Table 5 Change in total confidence scores in sub-groups of intervention group between pre- and post-training

\begin{tabular}{|c|c|c|c|c|c|c|}
\hline Items & & Number & $\begin{array}{l}\text { Pre-DVD } \\
\text { mean (SD) } \\
\text { (range 0-80) }\end{array}$ & $\begin{array}{l}\text { Post-DVD } \\
\text { mean (SD) } \\
\text { (range 0-80) }\end{array}$ & $\begin{array}{l}\text { ANOVA } \\
\text { (interaction effect) }\end{array}$ & $\begin{array}{l}\text { ANOVA } \\
\text { (within-subject effect) }\end{array}$ \\
\hline \multirow[t]{3}{*}{ Age } & $<30$ & 14 & $68.43(11.01)$ & $69.36(9.10)$ & \multirow{3}{*}{$\begin{array}{l}\mathrm{F}(2,48)=1.25 \\
p=0.30\end{array}$} & \multirow{3}{*}{$\begin{array}{l}F(1,48)=23.63 \\
p<0.01\end{array}$} \\
\hline & $30-39$ & 30 & $69.63(9.35)$ & $72.73(7.33)$ & & \\
\hline & $>39$ & 7 & $69.00(13.42)$ & $73.43(8.00)$ & & \\
\hline \multirow[t]{2}{*}{ Working hospital } & $\begin{array}{l}\text { Provincial /municipal } \\
\text { hospital }\end{array}$ & 30 & $68.67(10.38)$ & 72.10 (8.58) & \multirow[t]{2}{*}{$\begin{array}{l}F(1,67)=2.39 \\
p=0.13\end{array}$} & \multirow[t]{2}{*}{$\begin{array}{l}F(1,67)=22.31 \\
p<0.01\end{array}$} \\
\hline & County hospital & 39 & $64.82(11.76)$ & 71.59 (9.97) & & \\
\hline \multirow[t]{3}{*}{ Job type } & Nurse & 35 & 68.57 (9.73) & $71.43(8.50)$ & \multirow{3}{*}{$\begin{array}{l}F(2,66)=2.97 \\
p=0.06\end{array}$} & \multirow{3}{*}{$\begin{array}{l}F(1,66)=29.91 \\
p<0.01\end{array}$} \\
\hline & Midwife & 15 & $67.00(11.09)$ & $73.93(7.27)$ & & \\
\hline & Doctor & 19 & $62.26(13.32)$ & $70.84(12.09)$ & & \\
\hline \multirow[t]{2}{*}{ Job title } & Senior or mid-grade & 32 & $68.35(11.11)$ & 73.19 (7.49) & \multirow{2}{*}{$\begin{array}{l}F(1,67)=0.23 \\
P=0.64\end{array}$} & \multirow{2}{*}{$\begin{array}{l}F(1,67)=24.12 \\
p<0.01\end{array}$} \\
\hline & Primary & 37 & $64.34(11.24)$ & $70.22(11.00)$ & & \\
\hline \multirow[t]{2}{*}{ Years since qualification } & $\leq 5$ years & 28 & $65.89(11.45)$ & $71.11(7.63)$ & \multirow{2}{*}{$\begin{array}{l}F(1,66)=0.02 \\
p=0.89\end{array}$} & \multirow{2}{*}{$\begin{array}{l}F(1,66)=22.97 \\
p<0.01\end{array}$} \\
\hline & $>5$ years & 40 & $66.77(11.38)$ & $72.30(10.53)$ & & \\
\hline \multirow{3}{*}{$\begin{array}{l}\text { Years working with } \mathrm{BF}^{\mathrm{a}} \\
\text { mothers }\end{array}$} & $\leq 2$ years & 14 & $60.50(12.79)$ & $68.43(8.29)$ & \multirow{3}{*}{$\begin{array}{l}F(2,64)=0.89 \\
p=0.42\end{array}$} & \multirow{3}{*}{$\begin{array}{l}F(1,64)=24.43 \\
p<0.01\end{array}$} \\
\hline & $3-10$ years & 24 & $67.21(10.26)$ & $72.46(7.35)$ & & \\
\hline & $>10$ years & 29 & $68.41(10.81)$ & $72.41(11.17)$ & & \\
\hline \multirow[t]{2}{*}{ Previous training on $\mathrm{BF}$} & Yes & 51 & $68.47(10.01)$ & $73.08(7.34)$ & \multirow{2}{*}{$\begin{array}{l}F(1,67)=1.23 \\
p=0.27\end{array}$} & \multirow{2}{*}{$\begin{array}{l}F(1,67)=23.58 \\
p<0.01\end{array}$} \\
\hline & No & 18 & $60.89(12.97)$ & $68.22(12.39)$ & & \\
\hline
\end{tabular}

${ }^{\mathrm{a}} B F$ Breastfeeding

Cases were deleted where there was missing data on the dependent variable

scores were not moderated by age, time working with breastfeeding mothers, job type, years since qualification, seniority (job title) and prior to breastfeeding training experience.This finding is similar to a study which assessed breastfeeding knowledge among 51 clinicians in a neonatal unit in England using a similar multiple choice test of knowledge, where personal and job variables similar to those in this study were not associated with differences in objectively assessed knowledge [36].

Further sub-group analysis shows a significantly higher mean knowledge score was found in specialist tertiary hospitals than in the less specialist local hospitals before DVD training. This is consistent with the findings from the study by Wang and colleagues who reported the area of maternal service to be one of the crucial factors influencing breastfeeding duration due to the different support services provided by professionals in different settings, based on 47,843 mother-infant pairs under two years of age in ten provinces of China [37]. In our study, significantly improved scores were achieved in both types of hospital, showing that a short training intervention may contribute to reducing this variation in the provision of breastfeeding support.

Other sources of unequal provision arise from the large economic differences between provinces. The eastern coast of China is more developed and has more high quality education in medicine than those in rural areas
[38]. If the results of this study can be achieved in these less prosperous areas, it may help to reduce the inequalities in breastfeeding training between low-income regions and richer areas of China. Further studies could test whether the breastfeeding DVD training achieves the same results when offered for home self study, enabling more clinicians to meet their personal learning objectives.

\section{Confidence in practice}

For those who completed the confidence measure, significantly increased total confidence scores were found in the intervention group between pre- and posttraining, but not in the control group. Also, there were no significant differences in the change of total confidence scores in each sub-group between pre- and posttraining. Our results are limited by the 48 participants who did not complete one of the measures of confidence. Neverthelss, these findings are consistent with other studies that show breastfeeding education interventions for clinicians significantly increase their confidence in practice [39-42]. Downie, Rakic and Juliff reported that the increased confidence among nurses and midwives continued after completing the intervention Lactation Advisor Program (LAP) in Australial [39]. Similarly, in England, midwives and health visitors had increased confidence after BFHI training, which they 
reported enabled them to be more confident in supporting breastfeeding mothers [43]. The authors of a synthesis of breastfeeding training interventions concluded that proficient skills and increased confidence in helping breastfeeding mothers among healthcare professionals can be improved by training interventions, and this may improve rates of duration and exclusivity of breastfeeding [25]. Further study in China is require to examine the effect of the increased confidence on improving professionals' practice in supporting mothers' breastfeeding skills, thereby increasing the breastfeeding duration and rate of exclusive breastfeeding.

\section{Limitations}

The retest of the breastfeeding knowledge in the study was conducted immediately after both groups were exposed to the DVD, so only a short term effect has been measured. And no measures have been made in this study of changes in clinical practice and in breastfeeding rates. The large amount of missing data in the confidence scales suggests that the measure may not be understood, and needs further methodological development for use in the Chinese population.

\section{Conclusion}

Overall, this study has shown that the low levels of knowledge in positioning and attachment and hand expression of a range of clinical staff who are regularly engaged in supporting breastfeeding mothers in Chinese hospitals with BFHI accreditation can be addressed by a short training DVD. This method may be suited to addressing training needs more widely in China due to its effectiveness on knowledge, and the feasibility and low cost to staff time for large numbers of staff. However, the effectiveness of the DVD training on improving professionals' knowledge and confidence in practice the longer term requires further study, and the translation of knowledgeable and confident practice into the support that mothers need to improve breastfeeding outcomes should be further examined in the future.

\section{Abbreviations \\ BFHI: Baby Friendly Hospital Initiative; CG: Control group; CUBA: Coventry University Breastfeeding Assessment tool; CU-BSSES: Coventry University Breastfeeding Support Self-Efficacy Scale; FIL: Feedback inhibitor of lactation; HE: Hand Expression; IG: Intervention group; NHFPC: National Health and Family Planning Commission; NPA: National Programme of Action for Children's Development; P \& A: Positioning and Attachment; WHO: World Health Organization}

\section{Acknowledgements}

The authors thank the professionals and managers in the study sites for their help in data collection and creating a data set.

\section{Funding}

The study arises from a PhD programme jointly funded by Coventry University and Woman's hospital, Medicine of Zhejiang University. The Mandarin version and original items in English of the Mini-CUBA (Coventry University Breastfeeding
Assessment), and the Breastfeeding DVD are jointly owned by Health Behaviour Research Limited and Coventry University, both gave permission for use in this study. The study is also supported by the grants from public technology application research project of Science and Technology Department of Zhejiang Province (grant number: 2017c33059) and Medical and health science and technology plan of Zhejiang Province (grant number: 2017KY097).

Availability of data and materials

The anonymised datasets used and/or analysed during the current study are available from the corresponding author on reasonable request.

\section{Authors' contributions}

YYM drafted the paper based on her PhD thesis, conducted the study, undertook the analyses. LMW created the original proposal for the study, supervised the research and commented on drafts. LQQ contributed to the design of the study, commented on Chinese health policy, and sponsored the research in China. JKA and NB supervised statistical analyses and contributed to drafts of the paper. All authors read and approved the final manuscript.

\section{Ethics approval and consent to participate}

The study was given ethical approval by Coventry University, UK (ref: P5842), and Zhejiang University, China (ref: 20120002). All the participants were provided with the participant information sheet and signed the consent forms to participate in the study.

Consent for publication

Not applicable.

\section{Competing interests}

The authors declare that they have no competing interests.

\section{Publisher's Note}

Springer Nature remains neutral with regard to jurisdictional claims in published maps and institutional affiliations.

\section{Author details}

'Women's hospital, School of Medicine, Zhejiang University, Xueshi Road 1\#, Shangchen District, Hangzhou, Zhejiang Province, China. ${ }^{2}$ The Open University, Walton Hall, Milton Keynes MK7 6AA, UK. ${ }^{3}$ University of Cambridge, Trinity Lane, Cambridge CB2 1TN, UK. ${ }^{4}$ Coventry University, Priory Street, Coventry CV1 5FB, UK.

Received: 26 April 2017 Accepted: 16 March 2018

Published online: 27 March 2018

\section{References}

1. Popkin BM, Adair L, Akin JS, Black R, Briscoe J, Flieger W. Breast-feeding and diarrheal morbidity. Pediatrics. 1990;86(6):874-82.

2. Klement E, Cohen RV, Boxman J, Joseph A, Reif S. Breastfeeding and risk of inflammatory bowel disease: a systematic review with meta-analysis. Am J Clin Nutr. 2004:80(5):1342-52.

3. Duijts $L$, Jaddoe V, Hofman A, Moll HA. Prolonged and exclusive breastfeeding reduces the risk of infectious diseases in infancy. Pediatrics. 2010;126(1):18-25.

4. World Health Organization. Effect of breastfeeding on infant and child mortality due to infectious diseases in less developed countries: a pooled analysis. Lancet. 2000;355(9202):451-5.

5. Khan J, Vesel L, Bahl R, Martines JC. Timing of breastfeeding initiation and exclusivity of breastfeeding during the first month of life: effects on neonatal mortality and morbidity - a systematic review and meta-analysis. Matern Child Health J. 2014;19:468-479.

6. World Health Organization: Evidence on the long-term effects of breastfeeding. 2007

7. Victora CG, Bahl R, Barros AJ, França GV, Horton S, Krasevec J, et al. Breastfeeding in the 21st century: epidemiology, mechanisms, and lifelong effect. Lancet. 2016;387(10017):475-90.

8. Saadeh MR. Global Strategy for Infant and Young Child Feeding WHO, Geneva. 2003;56:236-238.

9. Xu F, Qiu L, Binns CW, Liu X. Breastfeeding in China: a review. Int Breastfeed J. 2009;4(1) 
10. Cannon AM, Sakalidis VS, Lai CT, Perrella SL, Geddes DT. Vacuum characteristics of the sucking cycle and relationships with milk removal from the breast in term infants. Early Hum Dev. 2016;96:1-6.

11. White J. Patterns of knowing: review, critique, and update. ANS. 1995;17(4):73-86.

12. Knight $\mathrm{CH}$, Peaker M, Wilde CJ. Local control of mammary development and function. Rev Reprod. 1998;3(2):104-12.

13. Henderson A, Stamp G, Pincombe J. Postpartum positioning and attachment education for increasing breastfeeding: a randomized trial. Birth 2001;28(4):236-42.

14. Escott R. Positioning, attachment and milk transfer. Breastfeed Rev. 1989;14:31-6.

15. Becker GE, Cooney F, Smith HA. Methods of milk expression for lactating women. Cochrane Database Syst Rev. 2011;(12)

16. Clemons SN, Amir LH. Breastfeeding women's experience of expressing: a descriptive study. J Hum Lact. 2010;26(3):258-65.

17. Binns CW, Win NN, Zhao Y, Scott JA. Trends in the expression of breastmilk 1993-2003. Breastfeed Rev. 2006;14(3):5-9.

18. Morton J, Hall JY, Wong RJ, Thairu L, Benitz WE, Rhine WD. Combining hand techniques with electric pumping increases milk production in mothers of preterm infants. J Perinatol. 2009;29(11):757-64.

19. World Health Organization, UNICEF: Breastfeeding promotion and support in a baby-friendly hospital, a 20-hour course for maternity staff. 2009.

20. Duffy EP, Percival P, Kershaw E. Positive effects of an antenatal group teaching session on postnatal nipple pain, nipple trauma and breast feeding rates. Midwifery. 1997;13(4):189-96.

21. Woolridge MW. The 'anatomy' of infant sucking. Midwifery. 1986;2(4):164-71.

22. Wallace LM, Kosmala-Anderson J. A training needs survey of doctors' breastfeeding support skills in England. Matern Child Nutr. 2006;2(4):217-31.

23. Wallace LM, Kosmala-Anderson J. Training needs survey of midwives, health visitors and voluntary-sector breastfeeding support staff in England. Matern Child Nutr. 2007;3(1):25-39.

24. Ouyang $Y, X u Y$, Zhang Q. Survey on breastfeeding among Chinese female physicians and nurses. Nurs Health Sci. 2012;14(3):298-303.

25. Watkins AL, Dodgson JE. Breastfeeding educational interventions for health professionals: a synthesis of intervention studies. J SPEC PEDIATR NURS, 2010;15(3):223-32

26. Gavine A, MacGillivray S, Renfrew MJ, Siebelt L, Haggi H, McFadden A Education and training of healthcare staff in the knowledge, attitudes and skills needed to work effectively with breastfeeding women: a systematic review. Int Breastfeed J. 2017;12(6)

27. Wallace $L$. Bridging the breastfeeding knowledge gap. PRACT MIDWIFE. 2008;11(2):38.

28. Wallace LM, Dunn OM, Law S, Bryce C. A new approach to breastfeeding training. Pract Midwife. 2009;12(6):47-9.

29. Wallace $L M$, Hughes $E$, Law SM, Joshi P. Meeting the challenge of delivering high-quality breastfeeding training for all. Pract Midwife. 2011;14(1):20-2.

30. Wallace LM, Law SM, Joshi P, Hughes E. An organisation-wide approach to training community practitioners in breastfeeding. Community Pract. 2011; 84(6):31-4.

31. Cohen J: Statistical power analysis for the behavioral sciences. 1988.

32. Faul F, Erdfelder E, Lang A, Buchner A. GPower 3: a flexible statistical power analysis program for the social, behavioral, and biomedical sciences. Behav Res Methods. 2007;39(2):175-91.

33. Cohen JW. Statistical power analysis for the behavioral sciences: 2nd edition ed. Hillsdale: Lawrence Erlbaum Associateds; 1988.

34. Pallant J. SPSS survival manual: a step by step guide to data analysis using IBM SPSS: 5th edition ed. Australia: Allen \& Unwin Book Publishers; 2013.

35. Wang L, Guo S, Zhang W, Zhao W, Wu J. Correlation between quality of maternity service and breastfeeding rates at discharge hospitals. Chin J Perinatal Med. 2002;4:256-60.

36. Wallace LM, Higman W, Blake K, Law S, Anwar K. Assessing the knowledge and confidence to perform breastfeeding practices in the neonatal unit-a case study of the use of the neonatal unit clinician assessment tool (NUCAT) in Coventry, England. J Neonatal Nursing. 2013;19(4):154-61.

37. Wang J, Li N, Xie S, Yang S, Zheng X, Zhang J. Duration of breastfeeding and its relevant influencing factors on under 2-years-old in rural areas of 10 provinces in China. Zhonghua Liu Xing Bing Xue Za Zhi. 2013;34(7):682-5.

38. Peng Y, Wu X, Atkins S, Zwarentein M, Zhu M, Zhan XX, Zhang F, Ran P, Yan WR. Internet-based health education in China: a content analysis of websites. BMC Med Educ. 2014;14(1):16-24.

39. Downie J, Rakic $V$, Juliff D. Enhancing the ability of nurses and midwives to promote breastfeeding: a longitudinal study. BIRTH ISSUES. 2002;11(2):53-9.
40. Khoury AJ, Hinton A, Mitra AK, Carothers C, Foretich C. Improving breastfeeding knowledge, attitudes, and practices of WIC clinic staff. Public Health Rep. 2002;117(5):453-62.

41. Kronborg H, Vaeth $\mathrm{M}$, Olsen J, Harder I. Health visitors and breastfeeding support: influence of knowledge and self-efficacy. Eur J Pub Health. 2008; 18(3):283-8.

42. Hillenbrand KM, Larsen PG. Effect of an educational intervention about breastfeeding on the knowledge, confidence, and behaviors of pediatric resident physicians. Pediatrics. 2002;110(5):7p.

43. Ingram J, Johnson D, Condon L. The effects of baby friendly initiative training on breastfeeding rates and the breastfeeding attitudes, knowledge and self-efficacy of community health-care staff. Prim Health Care Res Dev. 2011;12(3):266-75

\section{Submit your next manuscript to BioMed Central and we will help you at every step:}

- We accept pre-submission inquiries

- Our selector tool helps you to find the most relevant journal

- We provide round the clock customer support

- Convenient online submission

- Thorough peer review

- Inclusion in PubMed and all major indexing services

- Maximum visibility for your research

Submit your manuscript at www.biomedcentral.com/submit 